\title{
Concessive Conditionals Without Even if and Nonconcessive Conditionals with Even if
}

\section{Gilberto Gomes ${ }^{1}$}

Received: 18 April 2019 / Accepted: 10 July 2019 / Published online: 23 July 2019

(C) Springer Nature B.V. 2019

\begin{abstract}
This paper investigates whether even if $A, B$ is pragmatically polysemic, so that a nonconcessive conditional may have even if, and whether concessive conditionals, pragmatically defined, can fail to have even if or a non-temporal still. Different paraphrases are used to help elucidate pragmatic meanings. A theory of the pragmatic meanings of concessive and implicative conditionals is presented. The semantic meaning of even if and the question of whether concessive conditionals imply the truth of their consequents are also discussed.
\end{abstract}

Keywords Conditionals - Concessive conditionals · Implicative conditionals · Even if . Paraphrases · Differential paraphrasability

\section{Introduction}

Does the form even if $A, B$ always have the same pragmatic meaning, or is it pragmatically polysemic? It is well known that a concessive conditional may have both even if and a non-temporal still, or only one of these. However, is it possible for a concessive conditional, pragmatically defined, to have none of these? Conversely, is it possible for a nonconcessive conditional to have even if or a non-temporal still, or both? Can the acceptability of different paraphrases be used to elucidate these different pragmatic meanings? Is the truth of the consequent really implied by a concessive conditional? Can a semantic account of even if distinguish even if conditionals that imply the truth of their consequents from those that do not? These are the questions that will be addressed in this paper, and a theory of the pragmatic meanings of concessive and implicative conditionals will be presented.

Gilberto Gomes

ggomes@uenf.br

1 PGCL - Graduate Program in Cognition and Language, UENF - Northern Rio de Janeiro State University, R. Lopes Quintas 100-605-I, Rio de Janeiro, RJ 22460-012, Brazil 


\section{Concessive and Nonconcessive Conditionals, With and Without Even if}

A typical concessive conditional may have even if or a non-temporal still, or both:

(1) If Boris had gone to the party, Olga would still have gone. (Lewis 1973: 35)

(2) Even if the Bible is divinely inspired, it is not literally true. (Bennett 2003: 32)

(3) Even if she asks me to stay, I will still go.

However, a sentence may fail to present either of these two markers and still be used to convey a concessive conditional thought, and thus be interpreted by the hearer:

(4) If it rains tomorrow there will not be a terrific cloudburst. (Adams 1975: 15)

(5) If Calvin was still holding her hand, she could not feel it. (L'Engle 1962: 110, quoted by König 1986: 239)

(6) I wouldn't marry you if you were the last man on earth. (Haiman 1986: 216)

(7) I'll climb that mountain if it kills me. (Sweetser 1990: 136)

(8) If Gore is not happy, he will be permitted to go on residing in the United States. (Lycan 2001: 32)

Conversely, a sentence may present one or both of these markers without pragmatically having a concessive conditional value:

(9) He would be fired even if he drank just a little. (Pollock 1976: 30)

An example with still:

(10) If he gets a D, he will still pass, but not if he gets an F.

Although this sentence includes a non-temporal still in the consequent, it is not pragmatically a concessive conditional if, as a rule, students who get an $\mathrm{A}$, a $\mathrm{B}$, a $\mathrm{C}$ or a D pass, but not those who get an $\mathrm{F}^{1}$

\section{Semantic and Pragmatic Meanings}

Let me clarify what I am calling semantic and pragmatic meanings. Semantics has to do with what a linguistic expression means. Semantic meaning is the meaning that is common to all uses of a linguistic expression in a certain community at a particular time. When a linguistic expression is semantically polysemic, its uses fall into two or

\footnotetext{
${ }^{1}$ This example counters a claim by Barker (1991: 25), that still is the crucial word for indicating that the consequent is true. 
more classes, and each of its semantic meanings is the meaning shared by all uses within each of these classes. Semantics is involved with word or sentence meaning. Pragmatics pertains to how linguistic expressions are used; that is, it has to do with what the speaker means (and what the hearer understands the speaker means) when s/he uses a certain linguistic expression in a given situation. Thus, it is concerned with speaker meaning.

The pragmatics I have in mind in relation to conditionals is near-side pragmatics:

Near-side pragmatics is concerned with the nature of certain facts that are relevant to determining what is said. Far-side pragmatics is focused on what happens beyond saying (...) [O]n the near side of what is said, semantics and pragmatics are quite enmeshed. (...) what we are calling "near-side pragmatics," [involves] the way in which, in the setting of natural language, contextual factors interact with conventional meaning to determine what is said, or the proposition expressed. (Korta and Perry 2015).

I will not discuss the theories of the semantic meaning(s) of the word if or of the linguistic structure If $A, B$. It may suffice here to say that the latter roughly means In a case in which (it is true that) $A$, (it is true, or relevant to know, or to say, that) $B .{ }^{2}$ Here, I will only discuss a theory of the pragmatic meanings of If $A, B$ and of Even if $A, B$ (although some comments will be made on the semantics of even). I lack space, however, to explore all aspects of the theory and to counter all objections and counterexamples that might be raised against it, because the subject of conditionals is in itself very complex. A book would be needed to discuss the most relevant issues. I hope the reader will nonetheless be willing to consider the theory in relation to the aspects that will be addressed here and the light it sheds on the questions and examples that will be discussed.

\section{A Theory of the Pragmatic Meanings of Conditionals}

The starting point of the theory is the binary conjunctions of the affirmation $(\mathrm{A} ; \mathrm{B})$ or negation $(\sim \mathrm{A} ; \sim \mathrm{B})$ of the two component propositions (antecedent, $\mathrm{A}$, and consequent, $\mathrm{B})$ that form a conditional. There are four possible conjunctions of these: $\mathrm{A} \& \mathrm{~B}, \mathrm{~A} \& \sim \mathrm{B}$, $\sim \mathrm{A} \& \mathrm{~B}$, and $\sim \mathrm{A} \& \sim \mathrm{B}$. Different pragmatic meanings of if $A, B$ (or $B$ if $A$ ), according to the theory, correspond to different conjunctions of possibility claims (is possible or is impossible) about these binary conjunctions. Possibility and impossibility here are not necessarily logical or metaphysical, but may be merely empirical or practical. In fact, impossibility may just be improbability. Moreover, pragmatic possibility or impossibility is always relative to a certain context, to a certain set of probable or presupposed conditions.

All pragmatic types of conditionals share the claim that the conjunction $A \& B$ is possibly true, or at least possible to imagine as true. In fact, no conditional is true if

\footnotetext{
${ }^{2}$ To accept this, we have to admit that a case here is not a disguised form of saying all cases, for the latter would not work in the case of only if (see von Fintel 1997: 9). Lycan (2001: 11, 17) paraphrases If A, B as: In the event in which A, B, or In any event in which $A, B$.
} 
$\mathrm{A} \& \mathrm{~B}$ is impossible. Now, when is $\mathrm{A} \& \mathrm{~B}$ impossible? If $\mathrm{A}$ is impossible, or $\mathrm{B}$ is impossible, $A \& B$ is of course impossible. However, $A \& B$ may be impossible even if $\mathrm{A}$ is possible and $\mathrm{B}$ is possible. It must be emphasized, however, that, as I have stated earlier, I am not talking about logical possibility or metaphysical possibility, although some conditionals may involve these kinds of possibility. Impossible (not possibly true), here, does not necessarily mean something that entails a contradiction, as in logic, but simply something that is false in all the situations being considered. Similarly, necessary does not necessarily mean here something that cannot logically fail to be true, but simply something that is true in all the cases that are relevant for the context in which the conditional is stated.

Consider the following example:

(11) If they go to the movies tonight, they'll have a good time.

For this conditional to be true, it must be possible for them to go to the movies tonight, it must be possible for them to have a good time tonight, and it must be jointly possible for them to go to the movies and to have a good time tonight. Suppose the only film showing is one they will hate to see. Then it is possible for them to go to the movies, it is possible for them to have a good time (if they find something else to do, for example), but it may not be possible for them to both go to the movies and have a good time. If this is the case, the conditional will be false within this situation.

For counterfactuals, "possible" or "possibly true" is to be replaced by "possible to imagine as true." And how is this to be conceived? What should count as possible, or as impossible, to imagine as true? Here, I use the notion of possible worlds, partly as developed for conditionals by Stalnaker (1968) and Lewis (1973). A proposition is possible to imagine as true iff it is true in a possible world that is similar to the real world in all aspects relevant to the relation between A and B. Similarity defines the accessibility relation of possible worlds to the reference world (here, the actual world). The counterfactual world has to be sufficiently similar to the actual world for the counterfactual conditional to be useful and relevant. After all, when someone asserts a counterfactual conditional, s/he is not interested in a totally unreal and absurd world. Rather, s/he is trying to convey something about the actual world (Gomes 2013).

Suppose someone says, for example:

(12) If Mark had enough money, he would help Jean start up her business.

This conveys many things about the real world. First, that Mark does not have enough money to help Jean with her business. Second, that he will not help her with it. Third, that the reason why he will not help her is because he does not have enough money. This probably implies, fourth, that Mark would like to help Jean (or feels himself compelled to do so); i.e., that in the real world, he has a wish to do so, although he does not have the means to fulfill this wish. Still other ideas may be considered as suggested 
by this sentence (in a natural interpretation); for example, that Mark thinks it would be appropriate for him to help Jean, that he thinks it is a good thing for Jean to start up a business, etc.

In order to convey all these things about the real world, it is necessary that the unreal world imagined by the speaker and by the hearer is sufficiently similar to the real one. It is necessary that Mark, Jean, and her business project, in the counterfactual world, have all the relevant characteristics they have in the real world, except those that contradict what is described in the antecedent or what is necessarily derived from it. It would be useless to imagine Mark and Jean as completely different people from who they are, or to imagine Jean involved in a completely different business project. They must be as similar as possible to who they are in the real world. However, as Arregui (2009) has argued, only relevant aspects of the counterfactual world are involved in the similarity with the real world in relation to which counterfactual conditionals are evaluated. This is a point of difference between my view of possible worlds and Stalnaker's and Lewis's.

Rescher (2007), in his epistemic theory of conditionals, compares a conditional with an enthymeme (i.e., a syllogism with an unstated premise). In addition to the explicit antecedent, there are other unstated conditions that are necessary to arrive at the consequent. These implicit conditions may be considered as an unstated part of the antecedent. With regard to counterfactuals, he states: " $[\mathrm{H}]$ owever much the antecedent may be regarded as fanciful and false, the enthymematic basis of the conditional must be deemed true" (Rescher 2007: 7). In relation to our example (11), we might say: If Mark had enough money, and he had the same feelings towards Jean that he actually has, and Jean was planning to start the same business she is actually planning to start, and she had the same prospects of being successful that she actually has, etc., he would help her start up her business.

Now let us examine the second conjunction involving the affirmation or negation of the antecedent (A) and the consequent (B) of a conditional, namely A\& B. All types of conditionals except those with only if share the claim that $A \& \sim B$ is impossible. Again, it must be stressed that this impossibility is not necessarily a logical impossibility, or a metaphysical impossibility, or a physical impossibility, but may be merely an empirical or practical impossibility or improbability in a certain context, relative to a certain set of presupposed conditions or to a certain set of intentions.

Consider the example:

(13) If it rains tomorrow, I will not go out.

It is of course logically possible that it will rain and I will go out tomorrow. This is also metaphysically possible, and there is no physical law that prevents the co-occurrence of these two events. There might also be reasons that would make me change my mind and decide to go out in spite of the rain-for example, if my mother was ill, or if there was a fire in my apartment. However, what the speaker usually conveys with this sentence is that, under normal conditions, i.e., considering her/his present situation and her/his present intentions, although different things may happen tomorrow, and s/he 
may do different things, none of these circumstances includes her/his going out. What the speaker considers normal conditions, in relation to an indicative conditional such as this one, just as for counterfactuals, may be understood as an accessibility relation to possible worlds: in all possible worlds in which nothing exceptional occurs and in which it rains, $\mathrm{s} /$ he will not go out.

For Only if $A, B$ (more often, $B$ only if $A$ ) conditionals, $A \& \sim \mathrm{B}$ is usually possible and it is the third binary conjunction $\sim \mathrm{A} \& \mathrm{~B}$ that is impossible. Just as in classical propositional logic, therefore, there is a logical equivalence here between Only if $A, B$ and If $B, A$, although there may be differences in meaning between them.

Let me now introduce the concepts of implicative conditionals ${ }^{3}$ and of uniconditionals. I call implicative conditionals those in which the truth of the antecedent in a certain sense implies or is sufficient to indicate the truth of the consequent (Gomes 2009). Both implicative conditionals and only if conditionals (which are also implicative, but present the opposite direction of implication, from B to A) are subject to the phenomenon of conditional perfection, first noted by Ducrot (1969), and thus named by Geis and Zwicky (1971). Conditional perfection refers to the fact that If $A, B$ is often understood as also meaning and only if $A, B$; and Only if $A, B$ is often understood as also meaning and if $A, B$. This means that they often receive a biconditional interpretation. When they do not receive this biconditional interpretation, they may therefore be called uniconditional. (I also admit the possibility of an implicative conditional being vague or non-committal as regards the uniconditional/biconditional distinction.)

For the implicative uniconditional If $A, B$, the third conjunction $(\sim \mathrm{A} \& \mathrm{~B})$ is always possible, and for the Only if $A, B$ uniconditional (which is logically equivalent to the uniconditional If $B, A$ ), it is always impossible. As regards the second conjunction (A\& B), we may now say that it is always impossible for the uniconditional If $A, B$, and always possible for the uniconditional Only if $A, B$. By contrast, in a biconditional, which is the conjunction of two implicative conditionals (if $A, B$, and if $B, A$, or $A$ if and only if $B)$, both the second $(\mathrm{A} \& \sim \mathrm{B})$ and the third $(\sim \mathrm{A} \& \mathrm{~B})$ conjunctions are impossible. We can thus see that what is essential for the meaning of an implicative conditional is that the conjunction of the affirmation of the antecedent with the negation of the consequent is impossible, in the context in which the conditional is understood. The status of the conjunction of the negation of the antecedent with the affirmation of the consequent $(\sim \mathrm{A} \& \mathrm{~B})$ merely defines if it is interpreted as a uni- or a biconditional.

The fourth conjunction $(\sim \mathrm{A} \& \sim \mathrm{B})$ is always possible for implicative uniconditionals, only if uniconditionals, and biconditionals. Pragmatically, it would not make sense to say If $A$, if we did not recognize the possibility of $\sim \mathrm{A}$, or of imagining $\sim \mathrm{A}$. In addition, if we understand the truth of $\mathrm{B}$ as something we can infer from the truth of $\mathrm{A}$, either in the real world or in an imagined unreal possible world, we must also recognize the possibility of $\sim B$, or of imagining $\sim B$. If $\sim B$ were impossible, or impossible to imagine, it would be meaningless to establish a conditional relation between $\mathrm{A}$ and $\mathrm{B}$. And since $\mathrm{A} \& \sim \mathrm{B}$ is impossible (or impossible to imagine) in the context of an implicative conditional, $\sim \mathrm{A}$ and $\sim \mathrm{B}$ must be conjointly possible (or possible to imagine conjointly). If they were not, since $A \& \sim B$ is impossible, both $A \& \sim B$ and $\sim A \& \sim B$ would be impossible, and therefore $\sim \mathrm{B}$ itself would be impossible, in the context of the conditional.

\footnotetext{
${ }^{3}$ My use of the term is partly similar to and partly different from Declerck and Reed's (2001) use thereof.
} 
Finally, we must examine what conjunctions are possible or impossible for concessive conditionals, which most frequently have the form even if $A, B$. As for all other conditionals, $A \& B$ is possible for them ${ }^{4}$; and $A \& \sim B$ is impossible, just as for implicative uniconditionals and biconditionals. $\sim \mathrm{A} \& \mathrm{~B}$ is possible for concessive conditionals, just as for implicative uniconditionals. What makes the difference between concessive conditionals and implicative uniconditionals is the fourth conjunction, since for the latter $\sim A \& \sim B$ is possible, but for the former impossible, relative to the alternatives implicitly considered in a given context. This means that $\mathrm{B}$ is asserted as true, for all pragmatically concessive conditionals.

Consider example (3) (Even if she asks me to stay, I'll go). Suppose that everything that is relevant to my going or staying remains the same as it is now, except her asking me to stay (if this is the case), and the expected consequences of this. Under these circumstances, I will go, whether or not she asks me to stay. In other words, it is possible that she will ask me to stay but I will go (first conjunction), and it is possible that she will not ask me to stay and I will go (third conjunction); but it is not possible that I will not go, whether or not she asks me to stay (second and fourth conjunctions).

Beyond the possibility of the first and the third conjunctions, and the impossibility of the second and the fourth, there is another essential component of the pragmatic meaning of a concessive conditional. It is that the first conjunction is more surprising, unexpected, or noteworthy, or even merely more informative, or less probable, or more significant than the third. ${ }^{5}$ In other words, that $\sim \mathrm{A}$ is (or might be thought to be) more favorable to $\mathrm{B}$ than $\mathrm{A}$ is. This has to do with the meaning of the word even (see section 8), but may also be present in concessive conditionals without it. Concerning (4) (If Calvin was still holding her hand, she could not feel it), for example, it is more surprising that Calvin was still holding her hand and she could not feel it, than it would be for her not to feel it when Calvin was no longer holding it. In (6) (I would not marry you if you were the last man on earth), a hypothetical situation in which he is the last man on Earth and she does not marry him is more surprising than one (the actual one) in which he is not the last man on Earth and she does not marry him. (This counterfactual is not an idle statement about a catastrophic unreal world, but an emphatic way of telling the addressee that, in the real world, he does not have the slightest chance of marrying the speaker.)

This component of the meaning of a concessive conditional marks the difference between Even if $A, B$ and Whether or not $A, B$. If we hear the sentence Whether or not she goes, he'll go, we do not know if her going is favorable or unfavorable (or neither) to his going; we just know that he will go independently of her going or not. By contrast, the sentence Even if she goes, he'll go suggests, in addition, that it is less expected that he will go in a situation in which she will go than in a situation in which she will not.

Now let us examine the possibility or impossibility of the conjunctions of A or $\sim \mathrm{A}$ with $\mathrm{B}$ or $\sim \mathrm{B}$ in relation to (4) (If it rains tomorrow, there will not be a terrific

\footnotetext{
${ }^{4}$ Please always read (im)possible here as meaning (not) possibly true or (im)possible to imagine as true.

${ }^{5}$ Some authors consider that this component of the meaning of even if is semantic, others that it is pragmatic.
} 
cloudburst). It is possible that it will rain tomorrow and there will not be a terrific cloudburst (first conjunction), it is possible that it will not rain and there will not be a terrific cloud burst (third conjunction), but it is impossible (or very improbable), in the present meteorological conditions, that there will be a terrific cloudburst tomorrow, whether or not it rains (second and fourth conjunctions). In addition, it is obviously more informative to say that there will not be a terrific cloudburst in a situation in which it rains than in a situation in which it does not. We conclude that, although lacking the words even or still, (4) is a concessive conditional.

In relation to (9) (He would be fired even if he drank just a little), it is possible to imagine a situation in which he drinks even just a little and is fired (first conjunction), it is possible to imagine a situation in which he does not drink even just a little and is not fired (fourth conjunction), and it is also possible to imagine a situation in which he does not drink even just a little and is fired (for some other reason - third conjunction), but it is not possible to imagine a situation in which his boss is as similar as possible to the way s/he is in the real world and in which he drinks just a little and is not fired (second conjunction). (9) is therefore an implicative conditional, not a concessive one, even if it has even if.

In relation to the first conditional in (10) (If he gets a D, he will still pass, but not if he gets an $F$ ), it is possible that he gets a $\mathrm{D}$ and passes (first conjunction), it is possible that he does not get a $\mathrm{D}$ [but rather an $\mathrm{A}, \mathrm{a} \mathrm{B}$, or a $\mathrm{C}$ ] and passes (third conjunction) and it is possible that he does not get a D [but rather an F] and does not pass (fourth conjunction), but it is impossible that he gets a D and does not pass (second conjunction).

\section{Paraphrases for Implicative and Concessive Conditionals}

Let us now consider the paraphrases. Linguists are in general skeptical about paraphrases as a means of elucidating meaning. The fact that a linguistic expression can be paraphrased by another does not guarantee that the two expressions have the same meaning. However, when a linguistic expression in a given context accepts paraphrase A but not paraphrase B, and in a different context accepts paraphrase B but not paraphrase A, I think that a difference in its (semantic or pragmatic) meaning in the two contexts has been demonstrated, even if the accepted paraphrases, in their respective contexts, do not have exactly the same meaning as the original expression.

I propose that a sentence of the form if $A, B$ is pragmatically a concessive conditional iff:

(i) it already has or can be paraphrased with even before if;

(ii) it can be paraphrased with whether or not before the antecedent ${ }^{6}$; and

(iii) it cannot be paraphrased with any of the following before the consequent: (a) then as a consequence; (b) we can/could infer from this that; or (c) it's/it'd be because.

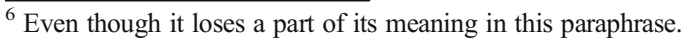


By contrast, it is pragmatically an implicative conditional iff:

(i) it accepts one of the paraphrases (a), (b), or (c), above, irrespective of the presence or the possibility of inserting even or still into the sentence; and

(ii) it cannot be paraphrased with whether or not.

For example:

(14) A: If it rains, the match will be cancelled.

B: No. If it rains, the match won't be cancelled.

Conditional (14)-A, in its usual interpretation, may be paraphrased as:

(15) If it rains, then as a consequence the match will be cancelled.

(16) If it rains, we can infer from this that the match will be cancelled.

And it cannot be paraphrased as:

(17) Whether or not it rains, the match will be cancelled.

By contrast, conditional (14)-B does not accept any of the following paraphrases:

(18) *If it rains, then as a consequence the match won't be cancelled.

(19) *If it rains, we can infer from this that the match won't be cancelled.

(20) *If it rains, it's because the match won't be cancelled.

But the following paraphrases are adequate:

(21) Even if it rains, the match won't be cancelled.

(22) Whether or not it rains, the match won't be cancelled.

Therefore, pragmatically, (14)-A is an implicative conditional and (14)-B is a concessive conditional.

Another example:

(23) If the garden is wet, it has rained. 
This accepts the following paraphrase:

(24) If the garden is wet, it's because it has rained.

By contrast, the following paraphrases are inappropriate:

(25) *Even if the garden is wet, it has rained.

(26) *Whether or not the garden is wet, it has rained.

Therefore, it is an implicative conditional.

With regard to (10), implicative paraphrases (a) and (b) are applicable. The first conditional of (10) can even be paraphrased as:

(27) Even if he gets a D, he will still pass.

A speaker might say this as a development of a previous sentence in which similar but less extreme conditions enabling one to pass were mentioned. For example: I think he will get an $A, a B$, or at least a $C$. Even if he gets $a D$, he will still pass, but not if he gets an F. Pragmatically, (27) is still an implicative, not a concessive, conditional, because it accepts the following paraphrases:

(28) Even if he gets a D, then as a consequence he will still pass, but not if he gets an $\mathrm{F}$.

(29) Even if he gets a D, we can infer from this that he will still pass, but not if he gets an $\mathrm{F}$.

Moreover, a paraphrase with whether or not would be inadequate:

(30) *Whether or not he gets a D, he will still pass, but not if he gets an F.

\section{The Adequacy of the Proposed Pragmatic Concept of Concessive Conditionals}

Why do I claim that such a concept of a pragmatically concessive conditional is adequate? König (1986: 229) makes the following contrast between a causal and a concessive:

a. Rich as he is, he spends a lot of money on horses. (causal)

b. Poor as he is, he spends a lot of money on horses. (concessive) 
A concessive is something that goes against the hearer's (or even the speaker's) expectations. It is something that the speaker concedes, although it goes against the point $\mathrm{s} /$ he wants to make. It is an argumentative concession. Similarly, the antecedent of a concessive conditional is a possibility that seems to go against the point that the speaker makes in stating the consequent. Thus, the consequent cannot really be seen as a consequence of the antecedent, or as something that we can enthymematically infer from the antecedent. In (14)-B and (21), for example, it is not because of the rain or as a consequence of the rain that the match will not be canceled but, on the contrary, in spite of the rain. By contrast, in (27), he will pass as a consequence of having earned a D. We cannot say that he will pass in spite of his getting a D (remember that it was assumed that, as a rule, a student who gets a $\mathrm{D}$ passes). Therefore, no concession is made by the speaker in uttering the antecedent.

Of course, someone who adopts a different concept may say that (27) is a concessive conditional. However, I argue that the concepts I propose are useful, because they enable a pragmatic distinction between two classes of conditionals that are used in very different ways. Moreover, it is simply a matter of empirical fact that a conditional belonging to the class of implicative conditionals thus defined may have even if or still.

One may think that even if implicative conditionals still have a concessive meaning, in the sense that in relation to (9), for example, it is less expected that he would be fired if he drank just a little than if he drank a lot. However, this is just part of the meaning of even, which in the case of conditionals, we have become used to associating with concessive meaning. In fact, even is not always concessive. Even John cried, for example, may be interpreted as conveying that it was less expected that John would cry, than that the others would cry, but the speaker is not thereby making a concession. Even if implicative conditionals still have the meaning of even, but they do not have the same pragmatic meaning of even if that concessive even if conditionals have.

\section{The Assertion of the Consequent in Concessive Conditionals}

Several authors have noted that concessive conditionals involve the assertion of their consequents (Mackie 1973; Pollock 1976; König 1986; Lycan 1991; Hunter 1993). Some prefer to say that they entail their consequent, that is, that their truth entails the truth of their consequent, while others prefer to say they merely suggest or implicate that. Pollock tells us that David Lewis questioned this claim with example (9) (He would be fired even if he drank just a little) (Pollock 1976: 30, 45). Bennett (2003: 268) also strongly opposes this claim, although he had previously supported that the truth of the consequent is sometimes required, not for the truth, but for the felicity of the assertion of an even if conditional (Bennett 1982). However, Lewis's counterexample is, according to my criteria, an implicative conditional with even if, rather than a concessive conditional (just as example (10) in section 2), and Bennett's (2003: 268) counterexample is a concessive conditional that is only conditionally asserted, so that it is unsurprising that its consequent is also only conditionally asserted (see below). 
We may question whether the consequent is also asserted as true in counterfactual concessive conditionals. In a counterfactual conditional, both the antecedent and the consequent are usually understood as false. If the same applies to a concessive counterfactual conditional, it cannot be the case that its consequent is understood as true. In other words, is it really the case that both $A \& \sim B$ and $\sim A \& \sim B$ are impossible in concessive conditionals, including counterfactual ones? The answer is yes, because in concessive counterfactual conditionals that are asserted as true, it is only the antecedent that is understood as contrary-to-fact - and for this reason Goodman (1947) called them semifactuals. For example:

(31) Even if I had a lot of money, I wouldn't buy this car.

This does not mean that the speaker will buy this car in the real world. The consequent states what will be the case about the relation between the speaker and the car in a possible unreal world in which s/he has a lot of money: s/he will not buy it. This is expressed with would because the speaker is talking about an unreal world; but the sentence also conveys that this is no different from what is the case in the real world. So the consequent is not counterfactual, but only the antecedent. The content of the consequent is implicitly asserted as true-in-the-real-world, even though it is expressed with would, which in other cases is used for saying something that is not the case. In all the possible worlds similar to the real world in all relevant aspects, in which the speaker has a lot of money, s/he will not buy that car, just as s/he will not buy it in the real world.

There are special contexts, however, in which the consequent seems not to be asserted. Let us examine the following example ${ }^{7}$ :

(32) If she were a fairy $[F]$, she could cast a spell $[S]$ even if she didn't have a magic wand $[\sim W]$.

Here, the consequent of the concessive conditional even if $\sim W, S$, namely she could cast a spell is counterfactual and thus not asserted as true. However, this sentence involves three clauses and two conditionals, and can be analyzed as: if $F$, then (even if $\sim W, S$ ). A concessive conditional is here the consequent of an implicative counterfactual - a linguistic expression that usually conveys that both the antecedent and the consequent are contrary-to-fact. If this is so, she is not a fairy, and the sentence Even if she did not have a magic wand, she could cast a spell is not true in the real world. Therefore, its consequent $S$ may also be false in the real world: she may be unable to cast a spell, since she is not a fairy. The concessive conditional would be true (and its consequent $S$ would also be asserted as true) if $F$ were true, but $F$ is false. This explains why the consequent $S$ is not asserted as true in (32): the concessive conditional itself is not asserted as true; on the contrary, the sentence conveys that it is false, but would be true in a counterfactual world in which she is a fairy. Even if the implicative conditional of such a two-conditional structure were not counterfactual, its consequent (the concessive

\footnotetext{
${ }^{7} \mathrm{I}$ am indebted to an anonymous reviewer for a counterexample upon which the following one was modeled.
} 
conditional) would not be asserted, but only conditionally asserted, and its consequent therefore also only conditionally asserted. And if we analyze the sentence as (if $F$, then $S$ ) even if $\sim W$, the consequent of the concessive conditional is now the implicative conditional, which is asserted.

Now let us consider a slightly different version of (32):

(33) Imagine she were a fairy. She could cast a spell $[S]$ even if she didn't have a magic wand $[\sim W]$.

Here (32) has been split in two and If was replaced with Imagine. Semantically, we now have only a counterfactual concessive conditional, in which the consequent is counterfactual and thus not asserted as true. Pragmatically, however, the set comprising the two sentences in (33) is equivalent to (32). The first sentence is used as a conditional protasis for the second. Therefore, there is only a conditional assertion of the second sentence and therefore only a conditional assertion of its consequent. If she were a fairy, as the first sentence invites us to imagine, then it would be asserted that she could cast a spell, whether or not she had a magic wand. Similar reasoning explains Bennett's (2003: 268) counterexample to the assertion of the consequent in concessive conditionals.

\section{The Meaning of Even in Even if}

It is controversial whether the contribution of even to the meaning of a sentence should be considered semantic or pragmatic, just as it is controversial how the distinction between semantics and pragmatics should be drawn (Iten 2002: 123). What contribution even makes to the meaning of a conditional is also controversial. With regard to our theory of concessive conditionals, however, these questions seem to be irrelevant, since concessive conditionals can be pragmatically characterized even in the absence of even, as shown in Sections 2 and 4. Nevertheless, most concessive conditionals have even if and it may therefore be useful to examine the meaning of even in both concessive and implicative conditionals.

Many authors have offered explanations for the meaning of even, as it occurs not only in even if sentences, but also in simple sentences like (34). This is not the place for an adequate review of the subject, however, and I will only pinpoint some conclusions and observations, and discuss how they relate to our view of concessive conditionals.

Even may focus on different parts of a sentence. In the following examples (from Lycan 2001), the focus of even is in italics:

(34) Even Grannie put on her coat.

(35) Grannie even put on her coat.

(36) Grannie put on even her coat.

(35) might be stated, for example, in the sequence of sentences: Grannie said she would go away. She even put on her coat. By contrast, (36) might be stated in the sequence: 
Grannie put on her sweater. She put on her jacket. She put on even her coat. Notice that in the previous examples, the focus of even comes immediately after it. This is not necessarily so, however. Someone could even more naturally have said, for example: Grannie put on her sweater. She put on her jacket. She even put on her coat. Here, the focus of even, determined by the context and indicated in oral language by subtle differences in intonation, is still (the garment) her coat, not (the action) put on her coat.

Even indicates that something is the case at an extreme point along a scale and that this is more unexpected (Fillmore 1965), more significant (Ducrot 1972), less likely (Karttunen and Peters 1979), more surprising (Bennett 1982; Barker 1991), more informative (Kay 1990), or more noteworthy (Bennett 2003) in comparison to what is the case at other, less extreme points. Pragmatic factors determine what scale is used as a reference. In relation to even if conditionals that are really concessive conditionals, I claim that only two situations need be compared: one in which both the antecedent and the consequent are true (A\&B) and the other in which the antecedent is false and the consequent is true ( $\sim A \& B)$. In pragmatically concessive conditionals, $\mathrm{A} \& \mathrm{~B}$ is more significant, informative, noteworthy, unexpected, unlikely or surprising than $\sim \mathrm{A} \& \mathrm{~B}$.

Concerning (31) (Even if I had a lot of money, I would not buy this car), for example, it is more significant for what the speaker wants to convey that, in an unreal situation in which s/he has a lot of money, s/he will not buy that car, than it is significant that, in the real world, in which s/he does not have a lot of money, $\mathrm{s} /$ he will not buy it. The former situation would be unexpected and surprising for some, and for that reason it is instrumental in showing something about the speaker's personality in the real world. For someone who asserts (2) (Even if the Bible is divinely inspired, it is not literally true), the possibility that the Bible is divinely inspired and not literally true is more remarkable that the possibility that it is neither divinely inspired nor literally true.

For implicative conditionals with even if, by contrast, the relevant reference scale may have more than two points. In relation to (27) (Even if he gets a D [D], he will still pass $[\mathrm{P}])$, it is only by reference to a scale that includes grades $\mathrm{A}, \mathrm{B}, \mathrm{C}$, and D that it makes sense to use "Even ... D ... still ...." D is the furthest point along this scale that allows a student to pass. The possibility that a student gets a $\mathrm{D}$ and passes is more significant or noteworthy than the possibility that $\mathrm{s} /$ he gets an $\mathrm{A}$, a B or a $\mathrm{C}$ and passes. Here, it is insufficient merely to compare the case in which both the antecedent and the consequent are true $(\mathrm{D} \& \mathrm{P})$ with the case in which the antecedent is false and the consequent true $(\sim \mathrm{D} \& \mathrm{P})$, because, in the latter case, he may not get a $\mathrm{D}(\sim \mathrm{D})$ but rather an $\mathrm{A}$, a B or a $\mathrm{C}$, or he may not get a $\mathrm{D}(\sim \mathrm{D})$ but rather an F. In the first possibility, $\sim \mathrm{D} \& \mathrm{P}$ (in fact, getting an $\mathrm{A}, \mathrm{a} \mathrm{B}$ or a $\mathrm{C}$ and passing) is less remarkable than D\&P, but in the second, $\sim \mathrm{D} \& \mathrm{P}$ (in fact, getting an F and passing), would be much more remarkable than D\&P.

The focus of even is sometimes instrumental in distinguishing a concessive even if conditional from an implicative one. In (9) (He would be fired even if he drank just a little), even comes before if, but its focus is just a little, as revealed in the equivalent paraphrase He would be fired if he drank even just a little. When the focus of even is just a part of the antecedent, the conditional does not assert its consequent, and that being so, it is an implicative and not a concessive conditional. What happens, however, when even focuses on the whole antecedent, or on if plus the antecedent? Here things are not so simple. 
Bennett (1982: 411) argues that an even if conditional "imply or signal the truth of the consequent" when the "scope" of even is the whole conditional clause (if plus the antecedent). According to Stephen Barker (1994: 249), "there is a class of even ifs signaling the assertibility of their consequents where even focuses if itself". Barker's example is this:

(37) I'll leave even if you leave. (Barker 1994: 250)

By contrast, Barker (1991: 15) states that, in other cases, even has the entire antecedent (without if) as its scope. He gives curious example. Suppose the speaker believes that if nothing happens, the cease-fire will continue, but if any upset occurs (even a trifling one), the cease-fire will end. S/he might then say:

(38) Even if the president were to get indigestion tonight, the cease-fire would end.

(Barker 1991: 15)

Here the consequent is not asserted, and the whole sentence is an implicative conditional.

We thus have here the idea of a contrast between the focus of even either on the antecedent (in implicative even if conditionals) or on 'if plus the antecedent' (in concessive ones). In symbolic language, these two cases could be rendered as: (i) if $e(A)$, [then] $B$; and (ii) $e$ (if A), [still] $B$ (where $e$ stands for even and the focus of even is within parentheses).

Corinne Iten (2002), after discussing previous theories of even and even if, presents her own account, based on Sperber and Wilson's (1986) Relevance Theory. According to Relevance Theory, a stimulus is relevant just in case it achieves a cognitive effect. However, cognitive effects come at a cost, so the cognitive principle of relevance means that humans pay attention to stimuli that yield the most cognitive effects for the least processing effort (Iten 2002: 133). Iten suggests that even encodes procedural meaning (Blakemore 1987), that is, it is an expression that constrain the inferential process involved in utterance interpretation, rather than mapping directly onto concepts or any other type of representation (Iten 2002: 136-137).

According to Iten, the procedural information encoded by even constrains the context in which its host utterance is processed, by indicating that the following instruction should be followed (where $S^{*}$ is sentence obtained by removing even from the original sentence, and $S_{j}$ is a sentence like $S^{*}$ where the focus of even in the original sentence was replaced by something similar, so that $S_{j}$ and $S^{*}$ are members of a certain scale that is contextually relevant):

Process $S^{*}$ in a context in which it is at the extreme end of a scale containing at least one assumption (i.e. fully propositional mental representation) different from $S^{*}$ in the element in the focus of even $\left(S_{j}\right)$, such that the truth of $S^{*}$ makes manifest or more manifest all assumptions on the scale. (Iten 2002: 152) 
Iten states that it is unimportant what the scale is a scale of, and stresses that it is not a scale of likelihood, but at the same time stipulates that it is a scale of pragmatic implication, where " $S^{*}$ implies the likely truth of any $S_{j}$, but not vice versa" (Iten 2002: 152). However, if $S^{*}$ implies the likely truth of any other member of the scale, while its likely truth is not implied by any of them (if this is what the author meant by vice versa), is this not after all a scale of likelihood?

Iten (2002: 153-155) claims that her theory is successful in cases in which one or another of the other theories she examines fails. She discusses the following example:

(39) Even if Neville passed the exam, he won't get the job. (Iten 2002: 148)

This is the analysis she provides, in which she gives an explanation for the fact that the sentence implies that the consequent is true:

[T] he scale that has to be accessed must contain at least one assumption of the form if $x$, Neville won't get the job which is such that it's made manifest or more manifest by the truth of If Neville passed the exam, he won't get the job. $S^{*}$ in this case is so extreme that it is highly likely that its truth implies the truth of any realistic assumption of the form if $x$, Neville won't get the job. In other words, it seems impossible to imagine an assumption of this form that is such that it would not be implied by $\mathrm{S}^{*}$. This is why (4) is felt to imply that Neville won't get the job.

What assumptions could we put on this scale, for example, along with If Neville passed the exam, he won't get the job [S*]? Perhaps one or more of the following: If Neville was sympathetic during the interview, he won't get the job. If Neville's CV is better than the others, he won't get the job. If Neville showed he is motivated for the job, he won't get the job. Let me first of all note that all of these sentences (including $S^{*}$ ) sound a bit strange, since we tend to interpret them as implicative conditionals. If this were the case, the employer would be looking for an unmotivated and unsympathetic candidate, who does not have a good CV and cannot pass the exam! For them to make sense, they must all be interpreted pragmatically as concessive conditionals, even though they lack the word even.

According to Iten's theory, we should be ready to accept that such assumptions (or similar ones) are made manifest (or more manifest than they already were) by the truth of $S^{*}$ (If Neville passed the exam, he won't get the job). It is not evident, however, that they are. Moreover, it seems that having to process this series of alternative assumptions goes against the principle of relevance, according to which the greatest cognitive effect should be achieved with the least processing effort. By my account, much less processing effort is required, since the relevant scale must include only two points, one of which is similar to $S^{*}$ (Possibly, Neville passed the exam and he will not get the job) and the other simply changes the first conjunct to the negative and repeats the second (Possibly, Neville did not pass the exam and he will not get the job). The comparison of these two conjunctions will very easily show that the first is more significant than the second, since the conjoint occurrence of not passing the exam and not getting the job is obviously less surprising than the conjoint occurrence of passing the exam and not getting the job. 
'Iten declares that it seems impossible to imagine an assumption of this form that would not be implied by $S^{*}$. However, I think this is not impossible at all: If Neville was the best candidate, he won't get the job is an assumption that seems not to be implied by (and to imply) $S^{*}$. According to the author, that impossibility would be the reason why (39) is felt to imply its consequent. According to my theory, the reason is simply that the concessive interpretation-merely suggested by even (semantics) and in fact required by the relation between the meaning of the antecedent and that of the consequent (pragmatics) - involves that the consequent (Neville won't get the job) is true in all the (two) situations considered (one in which he passed and the other in which he did not pass the exam). In fact, passing an exam is normally associated with increased chance of getting a job, and this relation is denied in (39), so the only interpretation available (already favored by even) is that of a concessive conditional.

Mathieu Vidal (2017) presents a formal semantics of if and of even, and a compositional formal semantics of even if. According to him, "both the focused element of even and its complement are parts of a more general set." Determination of the complement is left to pragmatics. The notion of scale involves an ordering of the elements of the set, in which the focused element occupies the lowest position. This means that "the belonging of the focused element to the general set is less expected than the belonging of its complement" (Vidal 2017: 252). According to the author, the truth conditions for Even John sleeps, for example, are (translating his formal symbols to plain language): (i) John sleeps; (ii) the other persons in the reference group sleep; and (iii) John is the least expected person of this group to be sleeping.

Vidal thinks that even and if in even if retain the same semantic meaning they have outside even if, that is, that the semantics of even if is compositional. However, the author himself acknowledges that " $[\mathrm{t}]$ he main question arising when we want to combine the previous semantics given for if and even is to determine what scale is at work in an even if conditional". The focus of even is taken to be the set of possible worlds determined by the antecedent. This is the lowest point on the scale. "However, what will be the remaining points on the scale?" To answer this question, he discusses an example (Even if it's windy, I go to the beach), and the considerations he makes are clearly pragmatic (whether the speaker dislikes the wind or whether she is a kite-surfer who needs the wind). He uses to the notion of universe of projection for the issue of determining the remaining points for the scale of the even if construction. The universe of projection corresponds to "a set of reasonable alternatives for the context at hand"again, an entirely pragmatic concept. The author himself admits that "this notion is partly vague, because we cannot say for each possible world whether it belongs to it or not" (Vidal 2017: 258-259).

After giving a formal definition for Even if A, B, Vidal (2017: 261) states:

The full meaning of the concessive conditional has three main parts. First, we can truly inhibit our belief in the antecedent and its negation (...). Second, both the antecedent and its negation lead to the same consequent (...). Third, the antecedent is a factor, less favorable than its negation, for the realization of the consequent (...).

There seems to be a partial similarity between these conditions and my own theory of concessive conditionals. When Vidal speaks of our being able to inhibit our 
belief in the antecedent or in its negation, perhaps this corresponds to the assumption that both the affirmation and the negation (or the truth and the falsity) of the antecedent are possible. When he says that both the antecedent and its negation lead to the same consequent, this may be roughly equivalent to the claim that both the first $(\mathrm{A} \& \mathrm{~B})$ and the third $(\sim \mathrm{A} \& \mathrm{~B})$ conjunctions are possible (see Section 4$)$. And when he characterizes the antecedent as a factor less favorable than its negation for the realization of the consequent, this is included in the condition that $\mathrm{A} \& \mathrm{~B}$ is more unexpected, or more significant for the point the speaker wants to make, than $\sim \mathrm{A} \& \mathrm{~B}$.

We may take for granted that the possibility of the second conjunction (A\& B), in the circumstances considered, is also denied in concessive conditionals, as it is in all conditionals. However, what is lacking, from my (pragmatic) point of view, is a consideration of the fourth conjunction $(\sim \mathrm{A} \& \sim \mathrm{B})$. This is the point of distinction between a concessive and an implicative reading of a conditional, whether with or without even if. If Mary dislikes the wind but says I'm going to the beach even if it is windy, then she considers it impossible, in the normal circumstances she is assuming, in which nothing exceptional occurs, that it will not be windy and she will not go to the beach. If she is going to the beach even if it is windy (which she dislikes), why would she not go if it is not windy?

By contrast, suppose Lucy is looking for an acceptable excuse to cancel a date and says: Even if it rains, I'll cancel the date. Here, the fourth conjunction ( A\& B) is possible, which shows this conditional to be implicative rather than concessive: it is possible that it will not rain, she will not be able to find any other acceptable excuse, and so she will not cancel the date. Raining is the lowest point on her scale of acceptability that is still sufficiently acceptable to be used as an excuse for canceling the date, and this is why she uses the word even. But this does not make her sentence a concessive conditional. Assuming that she is looking for an acceptable excuse to cancel the date, and that she considers the rain as such an excuse, her sentence can be paraphrased as Even if it rains, then as a consequence I'll cancel the date, but it cannot be paraphrased as Whether or not it rains, I'll cancel the date. By contrast, Mary's conditional (assuming the wind is an unfavorable condition for her going to the beach) could be paraphrased as Whether or not it's windy, I'm going to the beach and could not be paraphrased as Even if it's windy, then as a consequence I'm going to the beach.

Regarding Pollock's proposal that the meaning of a concessive conditional includes a simple affirmation of the truth of the consequent, Vidal argues as follows:

This position is supported when the scale of values described by the antecedent exhaust all the possibilities. In that case, the consequent is true in all circumstances. But the antecedent and its negation do not always cover all of the possible cases. Furthermore, the extent of this coverage is always relative to the circumstances of the assertion. (Vidal 2017: 261)

Thus, according to the author, the scale involved in the meaning of even if conditionals has the antecedent and its negation as its two extremities, ${ }^{8}$ and for

\footnotetext{
${ }^{8}$ This is a point of agreement between my theory and his, as far as concessive even if conditionals are concerned.
} 
some of them it covers all possible cases and for others it does not. In the first case, the consequent is asserted and in the second it is not. However, if the extent of this coverage is determined by the circumstances of the assertion, the distinction between these two classes of even if conditionals is pragmatic.

In relation to (9), Vidal (2017: 262) argues that the application of negation to the antecedent leads to the negation of the adverb: "By saying he didn't drink just a little, we mean that he drank a lot". His theory is thus in a better position than Pollock's to solve the problem posed by this example, because instead of admitting simply that the consequent is entailed, it states that "both the antecedent and its negation lead to the occurrence of the consequent". (This does not cover the possible case in which he did not drink at all.) However, the focus of even is not always only a part of the antecedent, as in this case. About (27) (Even if he gets a D, he will still pass), for example, we cannot say that both the antecedent and its negation lead to the occurrence of the consequent, because if he does not get a $\mathrm{D}$ he will not necessarily pass.

It is useful to consider two contrasting examples with the same antecedent:

(21) Even if it rains, the match will not be canceled.

(40) Even if it rains, the match will be canceled.

The antecedent and its negation being exactly the same in both cases, whether or not the scale includes all possibilities will be pragmatically determined by the context in which the Even if $A, B$ structure occurs. Here, the internal context, i.e. the meaning of the antecedent and of the consequent, is sufficient for the distinction. Raining may be a reason for canceling an open air match, so the antecedent in (40) (along with the enthymematic basis) indicates a sufficient condition for the truth of the consequent. By contrast, raining can hardly be a reason for not canceling a match, so the same antecedent, in (21), represents an insufficient condition for the falsity of the consequent (i.e., for canceling the match). We can say that both the antecedent and its negation lead to the occurrence of the consequent in (21), but not in (40). Note also that in the latter, the antecedent is more favorable to the realization of the consequent than its negation, contradicting Vidal's (2017: 261) third part of the meaning of a concessive conditional. This difference is not (and could not) be explained by any semantic theory. However, it is easily explained by my theory: in (21), it is impossible (in normal circumstances) that it will not rain and the match will be canceled $(\sim A \& \sim B)$, but in $(40)$, it is possible that it will not rain and the match will not be canceled $(\sim \mathrm{A} \& \sim \mathrm{B})$.

From the above discussion, we can see that the meaning of even is often relevant to the meaning of a concessive conditional. However, it is neither sufficient nor necessary to characterize a conditional as a concessive one. It is not sufficient, because even if may be present in a sentence without making it a concessive conditional. And it is not necessary, because a conditional may be concessive in the absence of even. The distinction between concessive and implicative conditionals is pragmatic, it is not derivable from the encoded meaning of even, whatever 
it is. No semantic theory will be able to explain the meanings of implicative and concessive conditionals, because they are not coded in natural language. We can very well create operators in a modal logic language for concessive and implicative conditionals, but natural language has not so far felt the need to create them, because it can very easily express the corresponding thoughts by means of pragmatics.

\section{Differential Paraphrasability}

Concerning paraphrases, it must be observed that they have often been used to elucidate meanings. With regard to conditionals, Lycan (2001: 17), for example, uses paraphrases to evidence the meanings of four conditional constructions:

$\mathrm{P}$ if $\mathrm{Q}=\mathrm{P}$ in any event in which $\mathrm{Q}$.

$\mathrm{P}$ only if $\mathrm{Q}=\mathrm{P}$ in no event other than the one in which $\mathrm{Q}$.

$\mathrm{P}$ even if $\mathrm{Q}=\mathrm{P}$ in any event including any in which $\mathrm{Q}$.

$\mathrm{P}$ unless $\mathrm{Q}=\mathrm{P}$ in any event other than one in which $\mathrm{Q}$.

See also the extensive use of paraphrases in Lycan (1991, section 4). It should be noted, however, that in these cases different paraphrases are used to reveal the different meanings of different linguistic expressions.

By contrast, the argument in this paper involves the use of different paraphrases for the same linguistic expression in different contexts, showing it to be pragmatically polysemic. This is what I call the principle of differential paraphrasability (already used in Gomes and Monken 2011), which may be expressed thus:

If the same linguistic expression $\mathrm{E}$ accepts paraphrase $\mathrm{P}$, but not paraphrase $\mathrm{Q}$, in context $C_{1}$, and accepts paraphrase $Q$, but not paraphrase $P$, in context $C_{2}$, then $E$ is pragmatically polysemic, since it can have two different meanings in different contexts, even if these two meanings are not identical to the meanings of P and Q, respectively.

I am not claiming this to be an original principle. It is possible that some author I am not aware of has already formulated it. What I claim is that it is a useful principle to investigate pragmatic polysemy.

We have found that the linguistic structure If $A, B$, in certain contexts, accepts implicative, but not concessive conditional, paraphrases, while in other contexts it accepts concessive conditional, but not implicative, paraphrases, revealing that it may have two different pragmatic meanings. Similarly, the linguistic structure Even if $A, B$ usually accepts a paraphrase with whether or not, but does not accept implicative paraphrases, whereas in other contexts it accepts implicative paraphrases, but not a paraphrase with whether or not. This shows that Even if $A, B$ is also polysemic and can have the same pragmatic meanings, of either a concessive or an implicative conditional, as the structure If $A, B$. 


\section{References}

Adams, E. W. (1975). The logic of conditionals. Dordrecht: G. Reidel.

Arregui, A. (2009). On similarity in counterfactuals. Linguistic and Philosophy, 32, 245-278.

Barker, S. J. (1991). Even, still and counterfactuals. Linguistics and Philosophy, 14, 1-38.

Barker, S. J. (1994). The consequent-entailment problem for even if. Linguistics and Philosophy, 17, 249-260.

Bennett, J. (1982). Even if. Linguistics and Philosophy, 5, 403-418.

Bennett, J. (2003). A philosophical guide to conditionals. Oxford: Oxford University Press.

Blakemore, D. (1987). Semantic constraints on relevance. Oxford: Blackwell.

Declerck, R., \& Reed, S. (2001). Conditionals: a comprehensive empirical analysis. Berlin: Mouton de Gruyter.

Ducrot, O. (1969). Présupposés et sous-entendus. Langue française 4: 30-43. Reprinted in: O. Ducrot, Le dire et le dit, 13-31. Paris: Les Éditions de Minuit, 1984.

Ducrot, O. (1972). Dire et ne pas dire: Principes de sémantique linguistique. Paris: Hermann.

Fillmore, C. J. (1965). Entailment rules in semantic theory. Ohio State University, Research Foundation, Project in Linguistic Analysis, Report No. 10, 60-82

Geis, M. L., \& Zwicky, A. M. (1971). On invited inferences. Linguistic Inquiry, 2, 561-566.

Gomes, G. (2009). Are Necessary and Sufficient Conditions Converse Relations?. Australasian Journal of Philosophy, 87(3): 375-387

Gomes, G. (2013). Pensamento e linguagem nas afirmações condicionais. DELTA: Documentação de Estudos em Lingüística Teórica e Aplicada 29(1): 121-134

Gomes, G., \& Monken, P. M. (2011). Postura epistêmica e parafraseabilidade diferencial em condicionais. Revista de Estudos da Linguagem, 19(2): 127-140

Goodman, N. (1947). The problem of counterfactual conditionals. Journal of Philosophy, 44(5), 113-128.

Haiman, J. (1986). Constraints on the form and meaning of the protasis. In C. E. Traugott et al. (Eds.), On conditionals (pp. 215-227). Cambridge: Cambridge University Press.

Hunter, G. (1993). The meaning of 'if' in conditional propositions. The Philosophical Quarterly, 43(172), 279-297.

Iten, C. (2002). Even if and even: the case for an inferential scalar account. UCL Working Papers in Linguistics, 14, 119-157.

Karttunen, L., \& Peters, S. (1979). Conventional implicature. In C. Oh \& D. Dineen (Eds.), Syntax and Semantics 11: Presuppositions. New York: Academic Press

Kay, P. (1990). Even. Linguistics and Philosophy, 13, 59-111.

König, E. (1986). Conditionals, concessive conditionals and concessives: areas of contrast, overlap and neutralization. In C. E. Traugott et al. (Eds.), On conditionals (pp. 229-246). Cambridge: Cambridge University Press.

Korta, K., \& Perry, J. (2015). Pragmatics. In E. N. Zalta (Ed.), The Stanford Encyclopedia of Philosophy URL $=<\mathrm{https}: / /$ plato.stanford.edu/archives/win2015/entries/pragmatics $/>$.

L’Engle, M. (1962). A wrinkle in time. New York: Dell Publishing Co..

Lewis, D. K. (1973). Counterfactuals. Cambridge: Harvard University Press.

Lycan, W. G. (1991). Even and even if. Linguistics and Philosophy, 14, 115-150.

Lycan, W. G. (2001). Real conditionals. Oxford: Oxford University Press.

Mackie, J. L. (1973). Truth, probability, and paradox. Oxford: Oxford University Press.

Pollock, J. L. (1976). Subjunctive reasoning. Dordrecht: D. Reidel.

Rescher, N. (2007). Conditionals. Cambridge: MIT Press.

Sperber, D., \& Wilson, D. (1986). Relevance: communication and cognition. Oxford: Blackwell.

Stalnaker, R. (1968). A theory of conditionals. In N. Rescher (Ed.), Studies in Logical Theory(American Philosophical Quarterly Monograph, 2 (pp. 98-112). Oxford: Blackwell.

Sweetser, E. (1990). From etymology to pragmatics. Cambridge: Cambridge University Press.

Vidal, M. (2017). A compositional semantics for 'even if' conditionals. Logic and Logical Philosophy, 26, 237-276.

von Fintel, K. (1997). Bare plurals, bare conditionals, and only. Journal of Semantics, 14, 1-56.

Publisher's Note Springer Nature remains neutral with regard to jurisdictional claims in published maps and institutional affiliations. 